\title{
A Review of Prospect Theory
}

\author{
Ze Pan \\ School of Management, Jinan University, Guangzhou, China \\ Email: pz1992@126.com
}

How to cite this paper: Pan, Z. (2019) A Review of Prospect Theory. Journal of Human Resource and Sustainability Studies, 7, 98-107. https://doi.org/10.4236/jhrss.2019.71007

Received: March 7, 2019

Accepted: March 25, 2019

Published: March 28, 2019

Copyright (C) 2019 by author(s) and Scientific Research Publishing Inc. This work is licensed under the Creative Commons Attribution International License (CC BY 4.0).

http://creativecommons.org/licenses/by/4.0/

\begin{abstract}
Behavioral decision derived from the paradox of the expected utility theory. With the introduction of cognitive psychology, it opened up a road for the field of behavioral decision. Now countless scholars are wandering in behavioral decision related with prospect theory, it is worth mentioning the prospect theory proposes Daniel Kahneman won the Nobel Prize in economics in 2002. It should be the recognition for his important contribution to the academic. This paper is a review of prospect theory.
\end{abstract}

\section{Keywords}

Prospect Theory, Decision, Function, Cumulative Prospect Theory

\section{Introduction}

Through a large number of experimental studies, behavioral psychologists have found that people's decisions are not always rational, and their risk attitudes and behaviors often deviate from the assumption of optimal behavior patterns in traditional economic theories. It is concluded that in the decision-making process, people not only have intuitive biases, but also have frame dependence biases, representativeness biases, availability biases, anchoring effects, cognitive differences and affected groups. Therefore, people often make different and contradictory choices for the same problem at different times.

Kahneman and Tversky [1] found that when making decisions with uncertainty, the ultimate utility of an individual is not simply the expected value of the possible future utility. The individual first edits the ultimate possible prospect (Kahneman and Tversky uses the word "prospect" specifically, which is different from the "expect" used in traditional expected utility theory. It emphasizes that the "prospect" is different from the simple "expectation") and then evaluates the edited prospect. They believe that individual psychological structure plays a key role in editing. 
More than 30 years later, prospect theory is still widely viewed as the best available description of how people evaluate risk in experimental settings. Kahneman and Tversky's papers on prospect theory have been cited tens of thousands of times.

Over the past decade, researchers in the field of behavioral economics have put a lot of thought into how prospect theory should be applied in various fields. This effort is bearing fruit. A growing body of empirical work tests the predictions of these new theories. In this essay, after first reviewing prospect theory and the difficulties inherent in applying it, I discuss some of this recent work. It is too early to declare this research effort an unqualified success, but the rapid progress of the last decade makes me optimistic that at least some of the insights of prospect theory will eventually find a permanent and significant place in various fields.

\section{What Is Prospect Theory}

Prospect theory believes that the individual doesn't value the final gains and losses to make decisions but the gains and losses relative to the reference point. According to this discovery, Kahneman and Tversky (1979) obtained a value function of gains and losses relative to the reference point. Furthermore, they point out that the expected utility function theory is too simple to use probability as the weight directly. Under uncertainty, the individual, instead of weighing the probability, adds up the possible value function in the future by decision weighting function, thus obtaining the final decision value of the individual.

\subsection{Decision Framework}

According to prospect theory (Kahneman and Tversky, 1979), investors will go through two stages when making selection and decision: Editing phase and evaluation phase. Editing stage of main function is to collect and organize information, and the corresponding pretreatment. It consists of four parts, which is data coding, data combination, data separation and data Cancellation. The second stage is the evaluation stage. In this stage, investors value and choose each edited prospect, and then choose the best prospect. The framework of investor decision-making under prospect theory is shown in Figure 1.

Kahneman and Tversky shift the traditional approach to assessing aggregate effects. They measure the total value of a prospect $(\mathrm{V})$, which is determined primarily by a combination of the value function (v) and the decision weight function

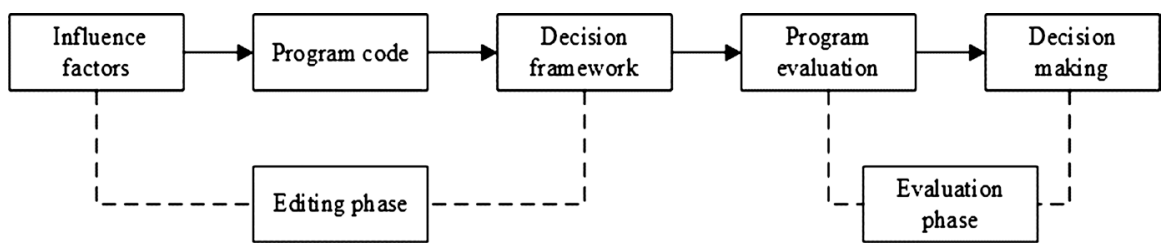

Figure 1. The framework of investor decision-making under prospect theory. 
$(\pi)$. The value function reflects the subjective value of the result, and the decision weight function represents the decision weight corresponding to the probability $(\mathrm{P})$ of the result, which is essentially different from the objective probability and reflects the influence of probability on the whole prospect value.

\subsection{Value Function}

The value function in prospect theory replaces the utility function in expectation utility theory. An important feature of value function is the existence of "reference point". The position of point $\mathrm{O}$ in Figure 2 is the reference point. When people evaluate a thing or make a choice, they will compare other certain reference objects intentionally or unintentionally. The comparison reference objects are different, even the same thing will get different results. Therefore, the value function values the variation value based on the reference point, namely "gain" and "loss". In addition to the definition of wealth change, the function curve is s-shaped, which is convex for "gains" and concave for "losses". As the development of both ends, the change of direction presents a decreasing trend of sensitivity. Moreover, it bends at the reference point. It is much steeper to the left of the reference point when the "loss" is small, compared to the case where the "gain" is small to the right of the reference point, as shown in Figure 2 below.

The value function converts surface values such as dollars into decision values. The specific form of value function proposed by Kahneman and Tversky is:

$$
v(x)=\left\{\begin{array}{ll}
x^{\alpha} & (x \geq 0) \\
-\lambda(-x)^{\beta} & (x<0)
\end{array} \quad v(\cdot) \pi(p)<p\right.
$$

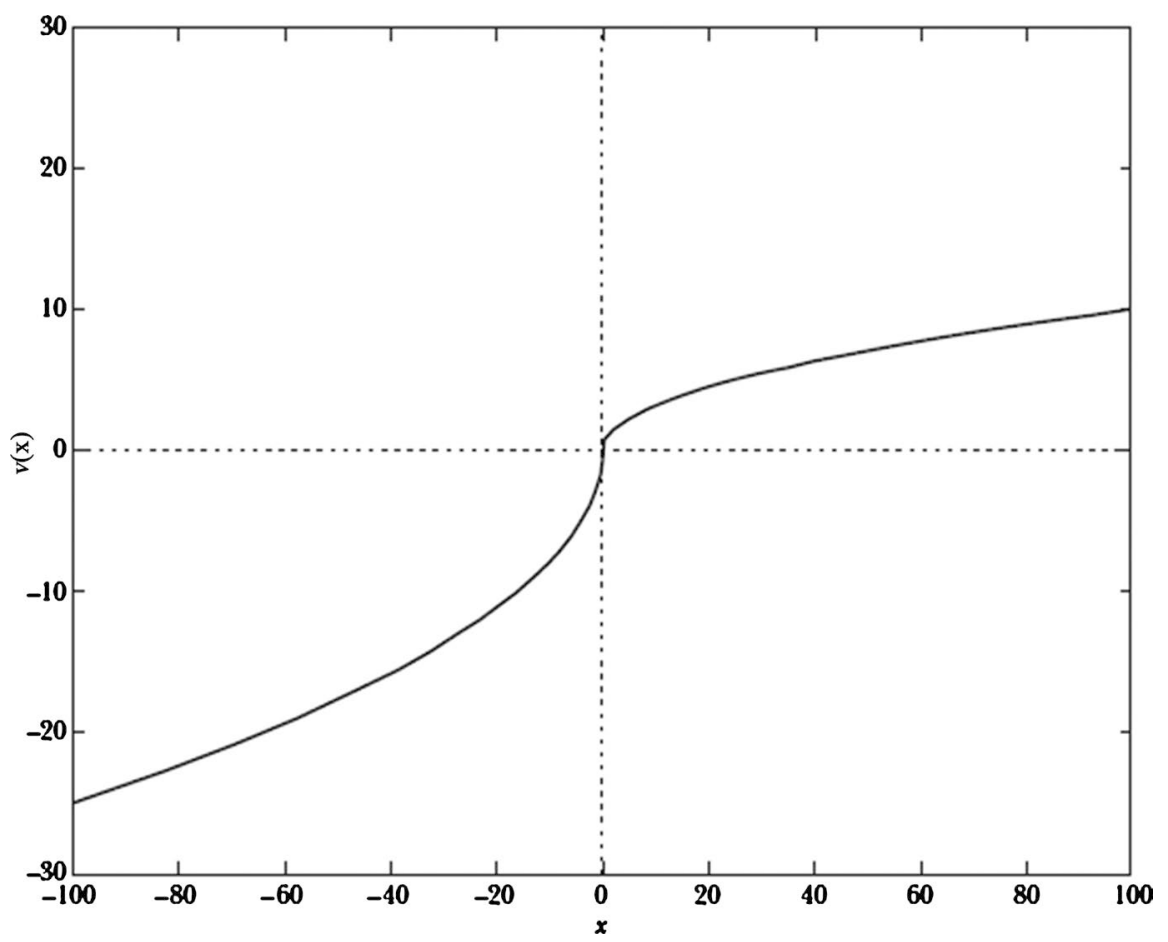

Figure 2. Value function. 
where $x$ is the gain and loss of the surface value, and the gain is positive and the loss is negative; $\alpha$ and $\beta$ are risk attitude coefficients, $0<\alpha<1,0<\beta<1$, the larger the $\alpha$ and $\beta$ are, the more risk prone the decision maker is; $\lambda$ is the loss aversion coefficient, or if it is $\lambda>1$, the decision maker is more sensitive to losses. $\Upsilon$ is the decision value, and obviously, $v(0)=0$.

\subsection{Weighting Function}

The decision weight function in prospect theory replaces the probability in expected utility theory. Decision weight is a kind of subjective judgment made by decision makers according to the probability of the occurrence of event results. It is not probability, nor does it follow the axioms of probability theory, but gives probability a weight, which can be regarded as the psychological probability of decision makers. Decision weight function has the following properties: $\pi(\rho)$ is the monotone function of $\rho$. For small probability, it always gives great weight, $\pi(\rho)>\rho$, And for the large probability is always given a small weight, that is, $\pi(\rho)<\rho$. Its general shape is shown in Figure 3.

The weight function converts probability into decision weight. As mentioned above, the profit and loss decision weights defined by Kahneman and Tversky are:

$$
\begin{aligned}
& \pi_{t}^{+}=w^{+}\left(\sum_{j=i}^{n} P_{j}\right)-w^{+}\left(\sum_{j=i+1}^{n} P_{j}\right) \\
& \pi_{t}^{-}=w^{-}\left(\sum_{j=1}^{i} P_{j}\right)-w^{-}\left(\sum_{j=1}^{i-1} P_{j}\right)
\end{aligned}
$$

where, $w^{+}$and $w^{-}$are non-linear weight functions of gains and losses respectively.

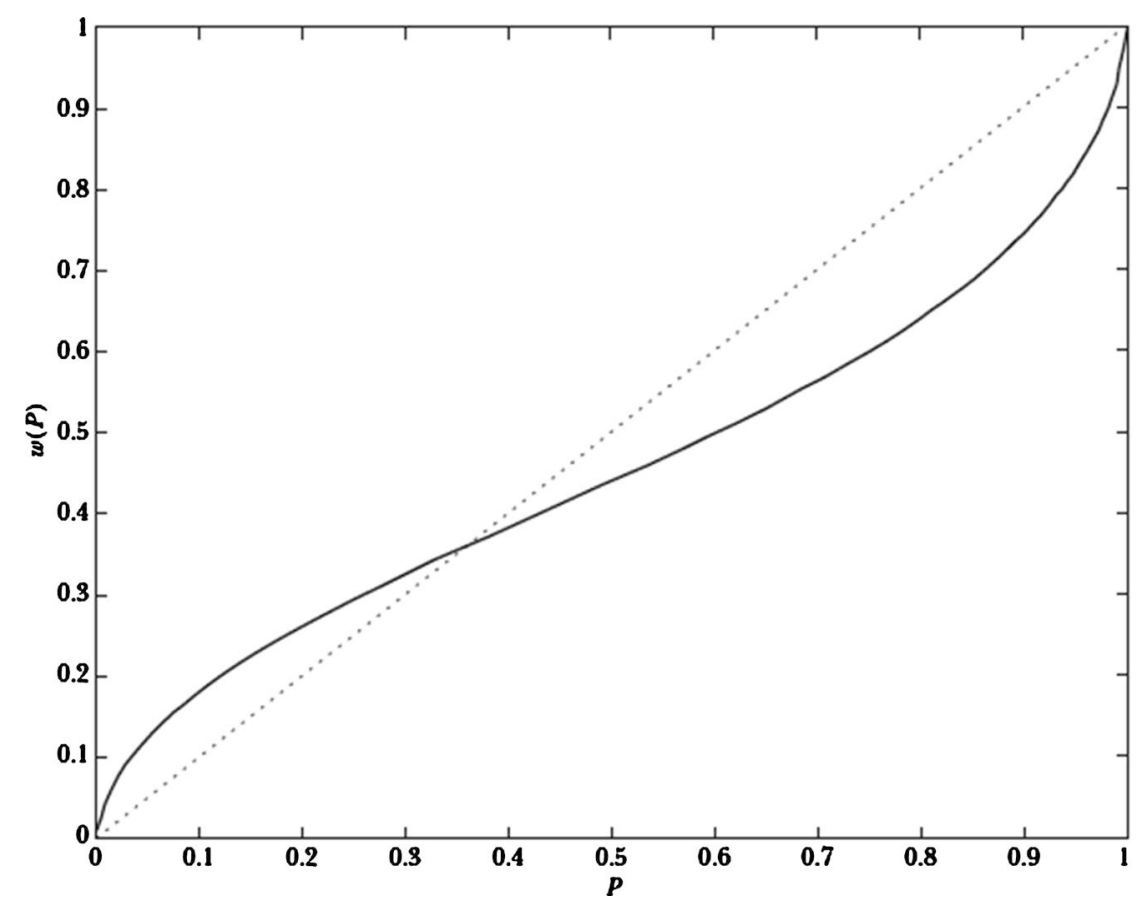

Figure 3. Weighting function. 
For situations where the risk outlook is two or more outcomes, the $w^{+}$and $w^{-}$ functions given by Prelec D (2005) are:

$$
\begin{aligned}
& w^{+}\left(\sum_{j=i}^{n} P_{j}\right)=\exp \left(-\gamma^{+}\left(-\ln \left(\sum_{j=i}^{n}\right) \varphi\right)\right. \\
& w^{-}\left(\sum_{j=1}^{i} P_{j}\right)=\exp \left(-\gamma^{-}\left(-\ln \left(\sum_{j=1}^{i}\right) \varphi\right)\right)
\end{aligned}
$$

where, $\gamma^{+}, \gamma^{-}$and $\varphi$ are parameters of the model, $\gamma^{+}>0, \gamma^{-}>0, \varphi>0$.

\subsection{Contributions}

To sum up, there are four main contributions of prospect theory:

1) People not only value the absolute amount of wealth, but also the change in wealth. Compared with the total amount of investment, investors are more concerned about the profit or loss of investment.

2) People are more inclined to take risks and gamble when faced with the prospect of loss with similar conditions (risk preference), while they are more inclined to achieve certain profits when faced with the prospect of profit with similar conditions (risk aversion).

3) The pain of a decrease in wealth is not equal to the pleasure of an increase in wealth by the same amount, and the former is greater than the latter.

4) The actual results of the early decision affect the later risk attitude and decision. The early profits can enhance people's risk preference and smooth the later losses. Early losses exacerbated the pain of later losses and increased risk aversion.

And there are two defects of prospect theory:

1) Prospect theory lacks the strict theory and mathematical deduction, only on people's behavior, so the prospect theory research can only make its descriptive is getting better and better, in other words, it just shows how people will do, and don't tell people how to do.

2) Prospect theory, as a descriptive model of decision-making under risk, has great application value and wide application scope. However, the current application research mainly focuses on the financial market, so the application scope needs to be expanded.

\section{The Development of Prospect Theory}

\subsection{Overview of Theoretical Development}

The development time line of prospect theory was roughly put forward in 1979, and developed by leaps and bounds in 1982. After the 1990s, hundreds of flowers blossomed. The following Table 1 clearly shows the development of prospect theory.

\subsection{Cumulative Prospect Theory}

On the basis of the prospect theory, Tersky and Kahneman (1992) [12] further 
Table 1. The development of prospect theory.

\begin{tabular}{|c|c|}
\hline Scholars and years & Theoretical content \\
\hline $\begin{array}{l}\text { Kahneman \& Tversky } \\
\text { (1979) }\end{array}$ & $\begin{array}{l}\text { Prospect theory: 1) Certainty results are found to be underestimated by } \\
\text { individuals compared with certainty results, which are known as certainty } \\
\text { effect. Certainty effect is also pointed out to be risk aversion of certainty } \\
\text { returns in selection and risk seeking of certainty losses in selection. 2) } \\
\text { Find the isolation effect, that is, when individuals are faced with the } \\
\text { problem of choosing between different perspectives, they will ignore the } \\
\text { part shared by all perspectives. }\end{array}$ \\
\hline
\end{tabular}

Quiggin (1982)

RUD (rank-dependent utility) theory: The weight assigned to a result is related not only to the probability of the result, but also to the sequence of each result relative to the other results [2].

Kahneman \& Tversky Cumulative prospect theory: The probability of capacity is introduced to (1992) solve the problem of strong dominance and multiple results processing. This makes the prospect theory get the essential promotion, greatly broadens its application scope and enhances its explanatory power.

Tversky \& Fox (1995) Decision theory is divided into risk outlook and uncertainty outlook, in which the probability of possible results in the risk outlook is known, but in the uncertainty outlook these probabilities are unknown [3].

Gonzalez \& Wu (1998) They Studied the shape of probability weighting function and analyzed two characteristic values of it, distinctiveness and elevation, from the point of view of psychology. According to these two eigenvalues, a weight function is constructed [4]:

$$
w(p)=\frac{\delta p^{r}}{\delta p^{r}+(1-p)^{r}}
$$

Humphrey (1999) Frequently occurring events, due to the high frequency of being remembered, tend to have an overestimated probability, which is mainly attributed to the deviation of coding events in memory (this deviation is caused by the limitation of memory capacity or the lack of adequate training) [5].

Langer \& Weber (2001) They extended the concept of myopic loss aversion to myopic prospect theory and predicted that for some specific venture capital business, myopia will not reduce but increase the attractiveness of investment results [6].

Gonzalez \& Wu (2003) The combination rules of PT and CPT are discussed. They pointed out that in bets with only two outcomes PT and CPT are the same, but in bets with three or more outcomes they are different [7].

Köszegi \& Rabin (2006) It provided a problem analysis tool for effectively defining "gain" and "loss" in various fields [8].

Fehr-Duda (2006) By studying the relationship between gender and risk taking, the author finds that there is a certain difference between men and women in weight function, but no significant difference in value function [9].

Schmidt \& Zank (2008) It is considered that strong risk aversion and concavity of value function are effective only when the condition of continuous probability weight function is satisfied [10].

Snowberg \& Wolfers The effective application of PT theory in gaming market is verified [11]. (2010)

proposed the cumulative prospect theory. Different from previous theories, Cumulative prospect theory is based on the rank-dependent function, or cumulative function. In the cumulative prospect theory, they summarized the pheno- 
mena violating the classical rational man hypothesis in the experiment into five categories:

1) Framing effects: In the traditional rational man hypothesis, the description of choice set does not affect the order of individual utility. However, experiments have shown that different organizational frameworks of choice sets have a systematic effect on individual preferences.

2) Nonlinear preferences: The traditional unascertainable expected utility function is a linear function with probability as the weight and different individual choices, but the experiment shows that this linear relationship is often broken.

3) Source dependence: They found that when dealing with uncertainty, individuals should consider not only the size of uncertainty, but also the source of uncertainty. That is, in the case of the same size of uncertainty, individual decisions may be different simply because of different sources of uncertainty.

4) Risk seeking: In contrast to the classical hypothesis about individuals, in some cases individuals may be risk-averse rather than risk-averse.

5) Loss aversion. They found that the fundamental uncertainty is that individuals are more sensitive to loss than to gain under the same conditions.

Based on these experimental results, Tersky and Kahneman (1992) revised the value function and weight function of the original prospect theory. In the end, they get a more specific s-shaped value function, and an anti-s-shaped weight function (a big change from the previous outlook theory), moreover, the value function and weight function are no longer independent. According to them, after comprehensive consideration of s-shaped value function and anti-s-shaped weight function, the individual finally presents four risk attitudes:

a) risk avoidance for benefits under high probability; b) seek for the risk of loss with high probability; c) seek for the risk of return under small probability; d) risk avoidance of loss with small probability.

\section{Application Fields}

Prospect theory is, first and foremost, a model of decision making under risk. As such, the most obvious places to look for applications are areas such as finance and insurance where attitudes to risk play a central role. We therefore start by discussing efforts to integrate prospect theory into these two fields and then turn to other areas. According to the number of published year, recently ten years it is rising until 2014, nearly four years slowed, may be a mature prospect theory, not the iconic new viewpoint is put forward. The application of the theory of value according to the number of related literature on is very high in Table 2 below brief introduction some reference of the related applications.

\section{Conclusions}

Reviewing the emergence and development of prospect theory, we can find that the framework of prospect theory has been formed, and it has better explanatory 
power to those phenomena that can't be explained by the theory of expected efficiency. From the point of view of the existing research, the focus is mainly on the value function, the specific form of the weight function and the determination of parameters. Relative "gains" and "losses" based on reference points are also applied in many fields. However, as can be seen from the literature review, the prospect theory may have some limitations in the following two aspects:

First of all, the value function and weight function need to be further studied. The existing theoretical model of prospect still has some phenomena inconsistent with the empirical evidence. The main reason is that the value function and the weight function have some subjectivity in the form selection, and there is no uniform method and standard in the function parameter fitting.

Secondly, prospect theory is also one of the main foundations of behavioral finance, but the current research is basically in the category of risk, and most of the research methods are using experimental data fitting or constructing discrete model simulation. There is not much research on the behavioral decision-making of enterprises in the market environment. If the relevant research

Table 2. Application fields of prospect theory.

\begin{tabular}{ll}
\hline Fields & Content \\
\hline Finance & Finance is the most widely applied field of prospect theory in economics. The \\
& research in this field applies prospect theory in three main cases: 1) the \\
& average return of cross section, the purpose of which is to understand why \\
& some financial assets have a higher average return rate than others; 2) the \\
& overall stock market; 3) traded financial assets [13]. \\
& In the area of insurance economics, prospect theory of risk attitudes plays a \\
Insurance & key role. So it is also a prospect theory and effective application fields. The \\
& most important consumers in the insurance market is property insurance and \\
& insurance against death (main product is life insurance and annuity), and \\
health care. So far, the prospect theory is used to explain the first two of three \\
markets [14]. \\
Köszegi and Rabin (2009) a prospect theory is put forward in the perspective \\
into a dynamic model of consumer choice. Early model based on the author's \\
ideas, when expectations are an important reference point, at each time t, \\
personal utility from two sources: 1) from the actual consumption at time t \\
and the man was recently expected consumption and 2) the difference \\
between a personal current consumption in each date in the future and the \\
difference between this person recently is expected [15].
\end{tabular}

Industrial enterprise When consumers have preferences of prospect theory, the company may adopt corresponding pricing strategy. Such as Heidhues and Köszegi (2014) considering the neutral monopoly for consumers with loss aversion in thoughts and money on the two dimensions of selling goods [16].

Labor supply $\quad$ Prospect theory may help to understand certain aspects of wage labor supply to reflect. The study of this subject is mainly concentrated in the taxi driver's labor supply. It may seem odd to focus on a narrow job market, but there is a reason. Labor supply models usually assume that workers can choose working time and quantity. Driving a taxi is a real professional [17].

Marketing

Pasquariello and Paolo studied equilibrium trading strategies and market quality in an economy in which speculators display preferences consistent with Prospect Theory [18]. 
model for the uncertainty of the natural environment can be adapted to the internal and external environment of enterprises, the prospect theory may also be developed.

Although this paper has made a systematic introduction to the prospect theory, including its theoretical content, development and application fields, there are still some deficiencies in the research, for example: 1) the model introduction of the prospect theory is not detailed enough; 2) there is a lack of reference materials about the recent progress of the prospect theory; 3 ) the application field of the prospect theory is not detailed enough.

At the end of the paper, the application scope of prospect theory is still expanding, but its disciplinary applicability is not enough. I plan to apply prospect theory to the field of product innovation for research. Then it can help enterprises reasonably judge and control the risk of product innovation, so as to improve the success rate and benefits of product innovation.

\section{Conflicts of Interest}

The authors declare no conflicts of interest regarding the publication of this paper.

\section{References}

[1] Kahneman, D. and Tversky, A. (1979) Prospect Theory: An Analysis of Decision under Risk. Econometrica, 47, 263-292. https://doi.org/10.2307/1914185

[2] Quiggin, J. (1982) A Theory of Anticipated Utility. Journal of Economic Behavior \& Organization, 3, 323-343. https://doi.org/10.1016/0167-2681(82)90008-7

[3] Fox, C.R. (2000) Ambiguity Aversion and Comparative Ignorance. In: Kahneman, D. and Tversky, A., Eds., Choices, Values, and Frames, Cambridge University Press, Cambridge, 585-603. https://doi.org/10.1017/CBO9780511803475.031

[4] Wu, G. and Gonzalez, R. (1998) Common Consequence Conditions in Decision Making under Risk. Journal of Risk and Uncertainty, 16, 115-139.

https://doi.org/10.1023/A:1007714509322

[5] Humphrey, S.J. (1999) Probability Learning, Event-Splitting Effects and the Economic Theory of Choice. Theory and Decision, 46, 51-78. https://doi.org/10.1023/A:1004984621705

[6] Langer, T. and Weber, M. (2001) Prospect Theory, Mental Accounting, and Differences in Aggregated and Segregated Evaluation of Lottery Portfolios. Management Science, 47, 716-733. https://doi.org/10.1287/mnsc.47.5.716.10483

[7] Gonzalez, R. and Wu, G. (2003) Composition Rules in Original and Cumulative Prospect Theory. Working Paper, Department of Psychology, University of Michigan, Ann Arbor, MI.

[8] Köszegi, B. and Rabin, M. (2005) A Model of Reference-Dependent Preferences. Quarterly Journal of Economics, 121, 1133-1165.

[9] Fehr-Duda, H., Gennaro, M.D. and Schubert, R. (2006) Gender, Financial Risk, and Probability Weights. Theory and Decision, 60, 283-313. https://doi.org/10.1007/s11238-005-4590-0

[10] Schmidt, U. and Zank, H. (2008) Risk Aversion in Cumulative Prospect Theory. Management Science, 54, 208-216. https://doi.org/10.1287/mnsc.1070.0762 
[11] Snowberg, E. and Wolfers, J. (2010) Explaining the Favorite-Long Shot Bias: Is It Risk-Love or Misperceptions? Journal of Political Economy, 118, 723-746. https://doi.org/10.1086/655844

[12] Kahneman, A.T. (1992) Advances in Prospect Theory: Cumulative Representation of Uncertainty. Journal of Risk and Uncertainty, 5, 297-323. https://doi.org/10.1007/BF00122574

[13] Green, T.C. and Hwang, B.H (2012) Initial Public Offerings as Lotteries: Skewness Preference and First-Day Returns. Management Science, 58, 432-444. https://doi.org/10.1287/mnsc.1110.1431

[14] Sydnor, J. (2010) (Over)Insuring Modest Risks. American Economic Journal Applied Economics, 2, 177-199. https://doi.org/10.1257/app.2.4.177

[15] Köszegi, B. and Rabin, M. (2009) Reference-Dependent Consumption Plans. American Economic Review, 99, 909-936. https://doi.org/10.1257/aer.99.3.909

[16] Heidhues, P. and Koszegi, B. (2014) Regular Prices and Sales. Theoretical Economics, 9, 217-251. https://doi.org/10.3982/TE1274

[17] Crawford, V.P. and Meng, J. (2011) New York City Cab Drivers' Labor Supply Revisited: Reference-Dependent Preferences with Rational-Expectations Targets for Hours and Income. American Economic Review, 101, 1912-1932. https://doi.org/10.1257/aer.101.5.1912

[18] Pasquariello, P. (2014) Prospect Theory and Market Quality. Journal of Economic Theory, 149, 276-310. https://doi.org/10.1016/j.jet.2013.09.010 